http://doi.org/10.48195/sepe2021-188

\title{
FLAGRANTES DA DIFÍCIL APLICAÇÃO DA PROTEÇÃO INTEGRAL EM DECISÕES JUDICIAIS PUBLICADAS NO SITE DO TJR/RS
}

Gabriela Freitas da Silva1; Rosane Leal da Silva²

\section{Eixo Temático: Direitos, Políticas Públicas e Diversidade}

\section{RESUMO}

Com a consolidação da teoria da proteção integral no ordenamento constitucional brasileiro, houve uma promessa de ruptura com as bases normativas anteriormente vigentes no sistema jurídico. A instauração dessa inovadora teoria acarretou 0 reconhecimento da figura da criança e do adolescente como sujeitos de direitos que, nessa condição, são merecedores de proteção que ultrapassam os direitos fundamentais destinados aos adultos, uma vez que exigem especial cuidado em razão do estágio de desenvolvimento que se encontram. Partindo desse reconhecimento, a pesquisa investiga a efetividade do marco teórico da proteção integral na prática das decisões do Tribunal de Justiça do Rio Grande do Sul a fim de examinar se a doutrina da situação irregular foi superada na prática forense, tendo em vista que são frequentes os flagrantes de violação. Para o desenvolvimento da pesquisa, fez-se o uso do método dialético, mais indicado para confrontar a realidade prática com a exposição das promessas normativas, o que foi aliado ao método de procedimento monográfico, utilizado para a realização da pesquisa jurisprudencial. Como conclusão, se abstrai que que ainda existem resquícios da doutrina da situação irregular na prática forense, com uso de terminologia inadequada e exposição de dados pessoais.

Palavras-chave: Paradigma protetivo; proteção constitucional; decisões judiciais.

\section{INTRODUÇÃO}

Influenciado pela Convenção Internacional sobre os Direitos da Criança, efetivou-se a construção e evolução do direito da criança e do adolescente no Brasil com a adoção, no ordenamento jurídico brasileiro, do paradigma da proteção integral. A partir desse marco, expandiu-se a atenção a esse novo ramo jurídico, que se manifestou como um importante objeto de proteção dos indivíduos em

\footnotetext{
${ }^{1}$ Graduanda em direito pela Universidade Franciscana e bolsista do Programa de Iniciação Científica (PROBIC) da instituição - freitasgfs6@gmail.com

${ }_{2}^{2}$ Doutora em direito pela Universidade Federal de Santa Catarina - rolealdasilva@gmail.com
} 
desenvolvimento. Entretanto, o conflito existente entre as inovações aderidas pela teoria da proteção integral como, por exemplo, o reconhecimento dos infantes e adolescentes como sujeitos de direito, e a doutrina anteriormente utilizada no sistema jurídico brasileiro - que indicava a discriminação em face desses sujeitos prejudica a efetivação, na prática, da nova teoria preconizada. Tal afirmação, facilmente observada na realidade diária, leva a que se estabeleça o seguinte problema de pesquisa: é possível afirmar que há flagrantes, na atuação do Tribunal de Justiça do Rio Grande do Sul, de manutenção do paradigma menorista?

Para o enfrentamento do tema apresenta-se este artigo, cujo objetivo é verificar possíveis flagrantes que denunciem, nas decisões judiciais, manutenção da doutrina da situação irregular, o que será feito por meio da análise de decisões do Tribunal de Justiça do Rio Grande do Sul publicadas em seu site. A presente pesquisa foi dividida de modo a abordar, no primeiro ponto, os elementos que caracterizam a doutrina da situação irregular e, em contraponto, as práticas que apresentam os flagrantes da doutrina da situação irregular ainda vigentes e apurados nos julgados do Tribunal Gaúcho.

\section{ELEMENTOS CARACTERIZADORES DA DOUTRINA DA PROTEÇÃO INTEGRAL}

O direito da criança e do adolescente sofreu diversas alterações até a consolidação jurídica nos moldes atuais. Dentre essas mudanças, a mais paradigmática refere-se à alteração das diretrizes condutoras de toda a gama relacionada à proteção legal assegurada a quem se encontra em período de desenvolvimento. Dessa forma, entende-se como necessária a explanação das características de cada uma dessas teses.

A Constituição de 1988 ergueu um novo modelo normativo, com a inserção de um capítulo na Carta Constitucional dedicado a positivar direitos à criança e ao adolescente, o que conferiu potencial influência para essa alteração paradigmática. Destaca-se em especial o artigo 227 da Constituição, que determina o princípio da prioridade absoluta como uma das diretrizes orientadoras desse novo ramo, que doravante iria reconhecer crianças e adolescentes como sujeitos de direito. 
A nova teoria preconizada pela ordem constitucional favoreceu o alinhamento do Brasil com os tratados internacionais de direitos humanos e com a Convenção Internacional dos Direitos da Criança, firmada em 1989 (CUSTODIO, 2008). A implementação da teoria da proteção integral no ordenamento constitucional brasileiro demonstrou o comprometimento dessa proposta inovadora em pactuar com diversos atores sociais na tarefa de assegurar proteção aos infantes e adolescentes a partir da atribuição de direitos aos sujeitos em formação. Nesse sentido, a Constituição Federal incumbiu à família, à sociedade e ao Estado a função de garantir a prioridade absoluta, a proteção integral e o melhor interesse aos sujeitos destinatários da norma. Com essa inovação legislativa, se depreende que também compete às figuras representantes da magistratura - como representantes do Estado na seara do Poder Judiciário - deterem o conhecimento dessas inovações a fim de assegurar os direitos das crianças e dos adolescentes e, ao aplicar o direito sempre indagar se a resposta jurisdicional a ser conferida naquele processo específico leva em conta a peculiar condição da criança/adolescente envolvido.

Somada à acepção de direitos pela Carta Magna, houve a regulamentação da Lei 8.069/90 com a finalidade de contemplar mais direitos aos indivíduos em destaque no novo cenário social. Sua condição de sujeitos de direitos impõe que seja levada em consideração a dignidade dessas pessoas que, conforme evidencia Ingo Sarlet (2009, p. 20), é "qualidade intrínseca da pessoa humana, é irrenunciável e inalienável, constituindo elemento que qualifica o ser humano como tal e dele não pode ser destacado [...]". Essa dimensão ontológica sustenta que é algo inerente a todo o ser humano e existe independentemente das circunstâncias externas, ainda que elas possam influenciar, negativa ou positivamente, a dignidade. Essas influências ocorrem em razão da dimensão intersubjetiva, pois como as pessoas estão em interação constante e vivem em sociedade é preciso ampliar o conceito para sustentar a necessidade de promover igual dignidade a todos.

Para que haja a efetivação das garantias relacionadas aos direitos supracitados, é imperativo que todos os agentes encarregados da proteção integral realizem a sua parte e responsabilizem-se, o que ainda não se alcançou. Tal constatação é ratificada tanto pelo número de violações que diariamente atingem 
essas pessoas vulneráveis e que atrapalham seu desenvolvimento quanto pelas respostas jurisdicionais no momento da resolução das demandas.

Quanto à análise da atuação do Poder Judiciário, em sede de decisões judiciais, percebe-se a ratificação do paradigma irregular pois, ao contrário do desejado, crianças e adolescentes tornam-se vulneráveis diante das decisões proferidas, em flagrante descompasso com a proteção integral e o mandamento de respeito à dignidade, ignorando-se o seu potencial de comandar o sistema jurídico a partir de fins e ideais que devem ser consagrados na prática (BARROSO, 2010 p.12).

À vista da imprescindibilidade de promover a aplicação, na prática, das novas garantias firmadas, o magistrado deveria pautar-se pelo princípio do melhor interesse da criança, segundo o qual há um dever de avaliar as melhores soluções de acordo com o interesse da criança no caso concreto, considerando a individualidade de cada sujeito (PEREIRA, 2000, p. 29). Sob esse prisma, o aspecto do melhor interesse da criança decorre da necessidade de examinar a adequação de medidas que afetem às crianças de modo a estimar, sobretudo, o interesse subjetivo dessas pessoas no campo de políticas públicas, decisões administrativas e decisões judiciais, por exemplo, conforme destaca o comentário 14 do Comité dos Direitos da Criança vinculado a Convenção sobre os Direitos da Criança (UNESCO, 2013, p. 17).

Nesse sentido, ressalta-se que o Poder Judiciário tem uma missão muito importante na promoção da proteção da criança e do adolescente, o que deve ser feito a partir das tendências da teoria da proteção integral com fundamentos relacionados ao melhor interesse da criança e do adolescente, dignidade da pessoa humana e execução dos direitos fundamentais desses sujeitos.

Portanto, com base na proteção integral passa-se a examinar decisões do Tribunal de Justiça do Rio Grande do Sul com a finalidade de certificar se há, na prática, o rompimento e a superação do uso de expressões e terminologias usuais no período de vigência da doutrina da situação irregular, tema que será enfrentado na sequência. 


\section{AS DECISÕES DO TRIBUNAL DE JUSTIÇA DO RIO GRANDE DO SUL: proximidade ou distanciamento da proteção integral?}

Sabe-se que a edição de leis não tem, por si só, o poder de alterar as realidades e produzir as mudanças necessárias. Essa situação também ocorre no caso da infância e adolescência, pois não basta a incorporação do paradigma da proteção integral no Estatuto da Criança e Adolescente se as práticas realizadas pelos encarregados em promovê-la, com ênfase neste trabalho para os julgadores, ainda se mantêm as mesmas.

É sobre este ponto que versará esta seção, cujo objetivo é evidenciar as decisões judiciais que ainda reproduzem terminologia inadequada, em franca desconsideração da condição de crianças e adolescentes como sujeitos de direitos.

Além da questão terminológica, que por si só já é reveladora, cogitou-se da existência de outros sinais de desrespeito a esses sujeitos de direitos, tais como a desconsideração com os dados pessoais de infantes e adolescentes, divulgados ao longo da decisão, bem como a desvalorização da atuação em rede, demonstrada pelo descaso pelos estudos psicossociais elaborados pela equipe interprofissional. A hipótese geral, portanto, era da existência de déficits na implementação da teoria da proteção integral, a revelar o abismo ainda existente entre a promessa normativa e a realidade.

\section{METODOLOGIA}

Partiu-se da hipótese de que o paradigma da proteção integral, normativamente adotado, ainda não se apresenta de forma geral, nas decisões judiciais. Para comprovar a hipótese realizou-se investigação doutrinárias sobre 0 tema, a qual foi complementada por investigação empírica, com coleta e análise de jurisprudências, utilizando para tanto um marco temporal que abarcou os últimos cinco (5) anos que antecederam a pesquisa, ou seja, as jurisprudências examinadas são restritas ao intervalo de tempo entre 2015 e 2020.

Para verificar a manutenção do paradigma menorista optou-se por duas categorias de análise que são reveladoras da objetificação de crianças e adolescentes, que ainda se mantêm: a) uso de terminologia inadequada e dispensa, 


\section{QUFN}

por parte do Poder Judiciário; b) exposição de dados pessoais de crianças e adolescentes, o que os torna vulneráveis, vez que a decisão é publicada no site do TJ/RS.

Assim, a partir da análise das decisões, compilou-se, na tabela a seguir, os principais aspectos negativos verificados. É necessário ponderar que as tabelas estão fragmentadas de acordo com as temáticas observadas, isto é, a primeira tabela refere-se a decisões cujo tema central é a suspensão e destituição do poder familiar, enquanto a segunda tabela faz menção às decisões sobre a prática do ato infracional.

\section{RESULTADOS E DISCUSSÕES}

Partindo dos critérios eleitos para a investigação, foram encontrados os seguintes "achados" nas decisões judiciais disponíveis no site do Tribunal de Justiça do Rio Grande do Sul, a revelar flagrantes da permanência, nas práticas forenses, da doutrina da situação irregular. 


\section{Temática: suspensão e destituição do poder familiar}

\section{Número do acórdão}

Acórdão 70084496140

https://www.tjrs.jus.br/novo/buscassolr/?aba $=$ jurisprudencia\&q $=70084496140 \&$ co nteudo_busca=ementa_completa

\section{Acórdão 70084396712}

https://www.tjrs.jus.br/novo/buscassolr/?aba=jurisprudencia\&q=70084396712\&co nteudo_busca=ementa_completa Acórdão 70084604339

https://www.tjrs.jus.br/novo/buscassolr/?aba=jurisprudencia\& $q=70084604339 \& c 0$ nteudo_busca=ementa_completa

\section{Acórdão 70084767334}

https://www.tjrs.jus.br/novo/buscassolr/?aba $=$ jurisprudencia $\&=70084767334 \& c o$ nteudo_busca=ementa_completa

\section{Acórdão 70084526433}

https://www.tjrs.jus.br/novo/buscassolr/?aba=jurisprudencia\&q=70084526433\&co nteudo busca=ementa completa

\section{Acórdão 70084792043}

https://www.tjrs.jus.br/novo/buscassolr/?aba=jurisprudencia\&q=70084792043\&co nteudo_busca=ementa_completa

\section{Flagrante da doutrina da situação irregular}

Há a revelação dos nomes de integrantes da família extensa da infante, dos genitores e da própria criança, o que revela dados pessoais.

Uso da terminologia "menor" para fazer referência a infante. Divulgação do primeiro nome dos genitores e da criança, o que pode permitir a identificação dos pais e da vítima.

Divulgação, na íntegra, do nome da criança, dos genitores e da avó.

Utilização da expressão "menor" com finalidade de fazer menção à criança. Além disso, há a identificação nominal da avó, da criança e de sua genitora. Cabe destacar, por fim, a divulgação da data de nascimento da infante que, em conjunto com a divulgação do nome completo das ascendentes, pode permitir identificar a identidade da criança.

Publicização da data de nascimento da infante. Ademais, percebe-se a citação dos nomes dos terceiros interessados para fins de adoção.

Uso da expressão "menor" como modo de fazer menção às duas crianças envolvidas no caso. Ademais, salienta-se a divulgação da data de nascimento dos infantes, bem como divulgação de seus nomes e de sua genitora. Além disso, fez-se a divulgação, na íntegra, dos nomes dos tios-avós que pleitearam a guarda de ambos.

Os resultados obtidos podem ser contrastados com as contribuições de Silva e Silva (2020) , que salientam a importância do tratamento cuidadoso de dados pessoais de crianças e adolescentes, informações que, se mal utilizadas, podem conduzir a discriminações. Assim, na atuação jurídica, em especial na área da 
infância e da juventude, deve-se observar padrões de cuidado, devendo o Estado também segui-los.

Os resultados apontam que a proteção da privacidade da criança e do adolescente ainda precisa ser aprofundada, sobretudo pela exposição de dados pessoais em decisões judiciais. Destaque-se que nas ações de destituição de poder familiar são discutidas matérias sensíveis, que evidenciam problemas na dinâmica das famílias, sendo frequentes casos de violência, dependência química e alcoolismo. Logo, a divulgação de dados pessoais que permitam identificar a criança ou adolescente em tela é tão violentador quando a ocorrência de provocou a judicialização do caso e merece ser considerada, sob pena de revitimizar a vítima.

\section{CONCLUSÃO}

Como já demonstrado, a área da infância e da adolescência exige um grau de sensibilidade de quem atua neste importante ramo, especialmente porque é permeada por complexidades. Usualmente, quando há uma criança ou adolescente enfrentando problemas de inserção em entidades de acolhimento em razão de seus pais terem perdido o poder familiar é porque o sistema de proteção já falhou e, antes de ser um problema com aquele ser em desenvolvimento o que se tem, na realidade, é um problema familiar e social.

Portanto, precisa ser compreendido que não há criança ou adolescente em situação irregular e sim ela está inserida numa situação ou condição que não Ihe permite o desenvolvimento e a fruição de seus direitos fundamentais. Antes de ser um problema dela, é um problema familiar, social e de ausência do Estado, todos atores encarregados de promover seus direitos.

A realidade demonstra, no entanto, que essa compreensão ainda não está formada e que o antigo paradigma da situação irregular e do menorismo ainda se mantém nos processos judiciais. Conforme demonstrado, após todas as situações de violência sofridas, a resposta jurisdicional também pode conduzir à nova violação. Ao tratar por "menor", o Poder Judiciário demonstra que precisa urgente atualização, não somente de seu vocabulário, mas também revisão urgente de suas práticas, pois a investigação revelou que as violações são também à privacidade dos 
envolvidos, pois ao fundamentar os processos muitas vezes o seu relatório acaba por divulgar dados pessoais de crianças e adolescentes e, ao assim agir, o Poder Judiciário não só reafirma sua objetificação, como também revela falta de sintonia com a recente Lei $\mathrm{n}^{\circ} 13.709$ de 2018, que tutela os dados pessoais, destinando um artigo específico a este grupo etário.

Portanto, é preciso dar efetividade à teoria da proteção integral e fazê-la viva e presente na resolução dos problemas envolvendo crianças e adolescentes. Cabe a cada jurista reescrever essa história de maneira a reconhecer a dignidade das crianças e adolescentes que dela são partes. Este é o desafio desta quadra da história.

\section{REFERÊNCIAS}

BARROSO, Luís Roberto. A Dignidade da Pessoa Humana no Direito

Constitucional Contemporâneo: Natureza Jurídica, Conteúdos Mínimos e Critérios de Aplicação. Versão provisória para debate público. Mimeografado, dezembro de 2010. Disponível em: http://www.professoraanafrazao.com.br/files/atividades docentes/2018-03-21Tema V Leitura III.pdf. Acesso em: 10 maio 2021.

CUSTÓDIO, André Viana. Teoria da proteção integral: pressuposto para compreensão do direito da criança e do adolescente. Revista do Direito, v. 29, p. 22-43, 2008. Disponível em:

http://online.unisc.br/seer/index.php/direito/article/viewFile/657/454. Acesso em: 15 ago. 2020.

PEREIRA, Tânia da Silva. O melhor interesse da criança: um debate interdisciplinar / coordenação Tânia da Silva Pereira. Rio de Janeiro: Renovar, 2000.

SARLET, Ingo Wolfgang. Dimensões da dignidade da pessoa humana: ensaios de Filosofia do Direito e Direito Constitucional. 2. ed. Porto Alegre: Livraria do Advogado, 2009.

SILVA, Rosane Leal da; SILVA, Fernanda dos Santos Rodrigues. Infância vigiada: p reconhecimento facial de crianças e adolescentes e os riscos da violação de seus dados pessoais. In: VERONESE, Josiane Rose Petry (Org.). Estatuto da Criança e do Adolescente 30 anos: grandes temas, grandes desafios. Rio de Janeiro: Lumen Juris, 2020, p. 41-66.

UNESCO. Comité dos direitos da criança. Comentário geral número 14 sobre o direito da criança a que seu interesse superior seja primacialmente tido em conta. Nações Unidas: 2013. 


\section{AGRADECIMENTOS}

Os agradecimentos das autoras à Universidade Franciscana, que concedeu a bolsa de iniciação científica - PROBIC. 